\title{
Spontaneous and Differentiation-Dependent Regulation of Measles Virus Gene Expression in Human Glial Cells
}

\author{
SIBYLLE SCHNEIDER-SCHAULIES, * JÜRGEN SCHNEIDER-SCHAULIES, MARION BAYER, \\ SIEGLINDE LÖFFLER, AND VOLKER TER MEULEN \\ Institut für Virologie und Immunbiologie, Universität Würzbung, \\ Versbacher Strasse 7, D-8700 Würbung, Germany
}

Received 21 January 1993/Accepted 2 March 1993

\begin{abstract}
The expression of measles virus (MV) in six different permanent human glioma cell lines (D-54, U-251, U-138, U-105, U-373, and D-32) was analyzed. Although all cell lines were permissive for productive replication of all MV strains tested, U-251, D-54, and D-32 cells spontaneously revealed restrictions of MV transcription similar to those observed for primary rat astroglial cells and brain tissue. In vitro differentiation of D-54 and U-251 cells by substances affecting the intracellular cyclic AMP level caused a significant reduction of the expression of the viral proteins after 18, 72, and $144 \mathrm{~h}$ of infection. This pronounced restriction was not paralleled to a comparable level by an inhibition of the synthesis and biological activity in vitro of virus-specific mRNAs as shown by quantitative Northern (RNA) blot analyses and in vitro translation. The block in viral protein synthesis could not be attributed to the induction of type I interferon by any of the substances tested. Our findings indicate that down-regulation of MV gene expression in human brain cells can occur by a cell type-dependent regulation of the viral mRNA transcription and a differentiation-dependent regulation of translation, both of which may be crucial for the establishment of persistent MV infections in the central nervous system.
\end{abstract}

\begin{abstract}
Measles virus (MV) has been identified as the etiological agent of subacute sclerosing panencephalitis (SSPE) and measles inclusion body encephalitis (31). Both diseases develop on the basis of a persistent infection of brain cells after incubation periods of months to years following primary infection. Molecular studies demonstrated characteristic restrictions of viral gene expression in the brain tissue of such patients at the level of both accumulation and translation of viral mRNAs affecting mainly the envelope genes coding for the matrix $(M)$, fusion $(F)$, and hemagglutinin $(H)$ proteins $(5,28)$. Similar observations have been made in studies of rats with subacute measles encephalitis, suggesting that the transcriptional down-regulation of MV occurs rather early in infection and is independent of long incubation periods (26). However, the mechanisms leading to the establishment of viral persistence and prevention of a lytic infection of brain cells are largely unknown.

To analyze further the MV-brain cell interactions, brain tissue culture cells are needed, since the complexity of the brain itself renders detailed studies in the central nervous system difficult. Using MV-infected primary rat astroglial cells, we recently confirmed a highly polar expression gradient for MV monocistronic transcripts in comparison with infected Vero cells, indicating an influence of host celldependent factors on the regulation of MV transcription in brain cells (27). For further characterization of these factors, however, primary rodent brain cell cultures are not suitable, since they are not natural host cells for MV and are available in only limited amounts. Therefore, it was necessary to establish a tissue culture system with human cell lines of neural origin that would allow us to study the regulation of MV transcription in a homologous system.

In this study we analyzed six MV-infected human glioma cell lines and found that three of them revealed transcrip-
\end{abstract}

\footnotetext{
- Corresponding author.
}

tional down-regulation of MV-specific monocistronic mRNA expression like that found in MV-infected human brain tissue. Moreover, we evaluated the effect of differentiating substances on MV replication in these cells, since it has been reported that the state of cell differentiation may influence MV gene expression $(18,25,35)$. On treatment with a variety of compounds affecting the intracellular cyclic AMP (cAMP) level, two of the human glioma cell lines differentiated and expressed glial cell-specific mRNAs. In these two cell lines, pretreatment with $10 \mu \mathrm{M}$ papaverine led to a drastic reduction of both virus release and synthesis of the virus-specific proteins. The steady-state levels of the corresponding mRNAs and their ability to translate in vitro were mostly unaffected, whereas translation in vivo was almost completely inhibited. Our data indicate that in contrast to the situation with nonneural cells, MV transcription can be down-regulated in human glioma cells by intrinsic host cell factors, whereas the translation of virus-specific proteins is influenced by the state of differentiation of the brain cells.

\section{MATERIALS AND METHODS}

Cells and viruses. Human glioma cell lines D-54, D-32, U-138, U-105, U-251, and U-373 were kindly provided by D. Bigner $(4,34)$. All cell lines were cultured in Dulbecco minimal essential medium containing $10 \%$ inactivated fetal calf serum FCS. Vero (African green monkey) and HEL (human embryonic lung fibroblast) cells were grown in minimal essential medium containing 5\% FCS. MV strains (vaccine strain Edmonston; neurotropic strain CAM/RBH [15]; wild-type strains Braxator, Woodfolk, and EVA; and SSPE isolates Lec, Halle, and Mantooth) were passaged and subjected to titer determination on Vero cells.

Treatment of cells with differentiating agents. Confluent monolayers were pretreated for the times indicated with AMP, cAMP, dibutyryl-cAMP, 8-bromo-cAMP, 8-(4-chlorophenylthio-cAMP) (CPT-cAMP), forskolin, isobutylmeth- 
TABLE 1. MV replication in human glioma cell lines and nonneural controls ${ }^{a}$

\begin{tabular}{|c|c|c|c|c|c|c|c|c|c|c|c|c|c|c|c|c|}
\hline \multirow{3}{*}{$\begin{array}{c}\text { Time p.i. } \\
\text { (h) }\end{array}$} & \multicolumn{16}{|c|}{ MV replication in: } \\
\hline & \multicolumn{2}{|c|}{ Vero } & \multicolumn{2}{|c|}{ HEL } & \multicolumn{2}{|c|}{ U-105 } & \multicolumn{2}{|c|}{ U-373 } & \multicolumn{2}{|c|}{ U-138 } & \multicolumn{2}{|c|}{ U-251 } & \multicolumn{2}{|r|}{ D-54 } & \multicolumn{2}{|r|}{ D-32 } \\
\hline & $\%^{c}$ & PFU & $\%$ & PFU & $\%$ & PFU & $\%$ & PFU & $\%$ & PFU & $\%$ & PFU & $\%$ & PFU & $\%$ & PFU \\
\hline $\begin{array}{l}72 \\
144\end{array}$ & $\begin{array}{c}95 \\
\mathrm{ND}^{e}\end{array}$ & $\begin{array}{c}1 \times 10^{7} \\
N D\end{array}$ & $\begin{array}{r}75 \\
100\end{array}$ & $\begin{array}{l}4 \times 10^{5} \\
5 \times 10^{6}\end{array}$ & $\begin{array}{r}75 \\
100\end{array}$ & $\begin{array}{l}1 \times 10^{5} \\
1 \times 10^{6}\end{array}$ & $\begin{array}{r}80 \\
100\end{array}$ & $\begin{array}{l}5 \times 10^{4} \\
1 \times 10^{6}\end{array}$ & $\begin{array}{r}85 \\
100\end{array}$ & $\begin{array}{l}5 \times 10^{4} \\
4 \times 10^{5}\end{array}$ & $\begin{array}{r}60 \\
100\end{array}$ & $\begin{array}{l}2 \times 10^{4} \\
1 \times 10^{6}\end{array}$ & $\begin{array}{r}50 \\
100\end{array}$ & $\begin{array}{l}2 \times 10^{4} \\
1 \times 10^{5}\end{array}$ & $\begin{array}{l}20 \\
80\end{array}$ & $\begin{array}{l}5 \times 10^{1} \\
4 \times 10^{3}\end{array}$ \\
\hline
\end{tabular}

a Cells were grown in duplicate assays on coverslips and infected with the Edmonston strain of MV (MOI, 0.05). After 72 and $144 \mathrm{~h}$, respectively, supernatants were harvested and subjected to titer determination on Vero ceils. Coverslips were fixed and stained by indirect immunofluorescence with an anti-MV hyperimmune serum, and the percentage of MV-positive cells was determined.

p.i., postinfection.

c Percentage of infected cells.

d PFU per milliliter (results are means from two independent experiments).

e ND, not done because cells were completely lysed.

ylxanthine (IBMX), or papaverine at concentrations ranging from $10 \mu \mathrm{M}$ to $1 \mathrm{mM}$. All substances were purchased from Sigma. Following infection with MV, the reagents were added fresh to the supernatants.

Immunostaining of MV-infected cells. Indirect-immunofluorescence analysis was performed on acetone-fixed MVinfected cells previously grown on coverslips by using a polyclonal rabbit anti-MV serum or monoclonal antibodies against $\mathrm{MV} \mathrm{N}, \mathrm{M}, \mathrm{F}$, and $\mathrm{H}$ proteins. As second antibodies, fluorescein-conjugated anti-rabbit or anti-mouse immunoglobulins (Dianova) were applied. For fluorescence-activated cell sorter analysis, cells were fixed with $0.5 \%$ paraformaldehyde and permeabilized with phosphate-buffered saline containing $4 \mathrm{mg}$ of $n$-octyl- $\beta$-D-glucopyranoside (Sigma) per $\mathrm{ml}$ as described previously (16).

RNA extraction, Northern (RNA) blots, and in vitro translation. For RNA extraction, $5 \times 10^{7}$ cells were lysed in $4 \mathrm{M}$ guanidinium isothiocyanate buffer and RNA was purified by centrifugation through a $\mathrm{CsCl}$ cushion, enriched for poly(A) RNA by one cycle of oligo(dT) selection, and analyzed for MV-specific monocistronic transcripts as described previously (26). cDNA probes specific for rat glyceraldehyde-3phosphate dehydrogenase (GAPDH) (11), rat myelin basic protein (MBP) (24), and mouse adhesion molecule on glial cells (AMOG) (21) were used as gel-purified fragments and labeled by random priming with $\left[{ }^{32} \mathrm{P}\right] \mathrm{dCTP}$ as specified by the manufacturer (Boehringer, Mannheim, Germany). Hybridization with the DNA probes was performed at $45^{\circ} \mathrm{C}$ followed by three wash steps in $0.25 \times$ SSC $(1 \times$ SSC is 0.15 $\mathrm{M} \mathrm{NaCl}$ plus $0.015 \mathrm{M}$ sodium citrate) $-0.1 \%$ sodium dodecyl sulfate (SDS) at $68^{\circ} \mathrm{C}$. Each $1-\mu \mathrm{g}$ portion of the isolated poly(A)-enriched fractions was translated in vitro in the presence of $30 \mu \mathrm{Ci}$ of $\left[{ }^{35} \mathrm{~S}\right]$ methionine in a rabbit reticulocyte lysate (Promega). MV-specific proteins were immunoprecipitated from total translation products by using a polyclonal rabbit anti-MV serum.

Metabolic labeling, preparation of cell extracts, and immunoprecipitation. Cells $\left(3 \times 10^{6}\right)$ were pretreated at approximately $75 \%$ confluency with $10 \mu \mathrm{M}$ papaverine for the indicated times prior to infection with $\mathrm{MV}$ and were labeled immediately or after various incubation periods. For labeling, cells were starved in methionine-free Dulbecco minimal essential medium for $1 \mathrm{~h}$ and subsequently labeled with 0.5 $\mathrm{mCi}$ of $\left[{ }^{35} \mathrm{~S}\right]$ methionine per $\mathrm{ml}$ for $2 \mathrm{~h}$. Total-cell extracts were prepared following lysis in RIPA detergent $(150 \mathrm{mM}$ $\mathrm{NaCl}, 10 \mathrm{mM}$ Tris- $\mathrm{HCl}$ [pH 7.4], $1 \%$ sodium desoxycholate, $1 \%$ Triton X-100, $1 \%$ SDS, $10 \mathrm{mM}$ phenylmethylsulfonylfluoride), incorporation was measured by liquid scintillation counting of trichloroacetic acid-precipitable material, and the protein content was determined by standard procedures (Sigma). Both equal counts and equal amounts of protein were immunoprecipitated when using rabbit anti-MV serum and separated by SDS-polyacrylamide gel electrophoresis (PAGE) (10\% polyacrylamide).

Western blot analysis. Unlabeled extracts were prepared as described above in RIPA detergent. Each $20-\mu \mathrm{g}$ portion of total-cell extract was separated by PAGE (10\% polyacrylamide) and transferred to nitrocellulose by semidry blotting. Western immunoblots were stained with a monoclonal anti-human MxA antibody (kindly provided by $\mathbf{M}$. A. Horisberger [13]) and with a peroxidase-conjugated rabbit anti-mouse immunoglobulin as the second antibody and developed with chloronaphthol in the presence of $\mathrm{H}_{2} \mathrm{O}_{2}$.

\section{RESULTS}

Replication of MV in human glioma cell lines and control cells. To characterize MV replication in cells of neural origin, six human glioma cell lines (U-105, U-373, U-138, U-251, D-54 and D-32) and, as controls, two cell lines of nonneural origin (Vero and HEL) were infected with the Edmonston strain of MV (multiplicity of infection [MOI], 0.05). Cells and supernatants were harvested at 72 and $144 \mathrm{~h}$ following infection to determine the percentage of infected cells and the titer of infectious virus. All neural cell lines tested allowed replication of MV and revealed a cytopathic effect. Most of them, however, produced less infectious virus than the control cell lines did (Table 1). In particular, in D-54 and D-32 cells the yield of infectious virus was reduced by a factor of more than $10^{2}$ and $10^{3}$, respectively, compared with Vero cells. Similar results were obtained with several different strains of MV including the wild-type isolates Braxator, EVA, and Woodfolk; the SSPE isolates Lec, Halle, and Mantooth; and the neurotropic strain CAM/RBH. Since our results were independent of the input virus, further experiments were carried out with MV Edmonston.

The polyadenylated RNA fractions of the six human glioma cell lines and the control cell lines and the control cell lines infected with MV (MOI, 0.05) for $24,48,72$ and $96 \mathrm{~h}$ were analyzed for the steady-state levels of MV-specific monocistronic transcripts by using quantitative Northern blots. The overall expression levels of MV-specific RNAs were reduced in all neural cell lines to about 13 to $60 \%$ of those found in Vero and HEL cells as determined by the expression of the $\mathrm{N}$-specific mRNA after $24 \mathrm{~h}$ (Fig. la). Furthermore, as shown representatively for $72 \mathrm{~h}$ postinfection, the transcription gradients obtained for the monocistronic MV transcripts differed among the individual cell lines 
a.

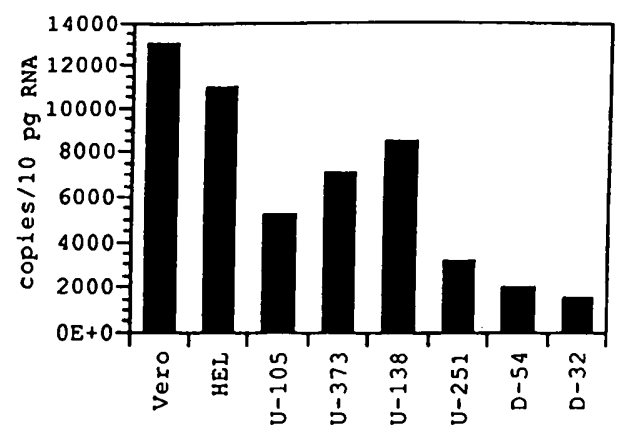

b.

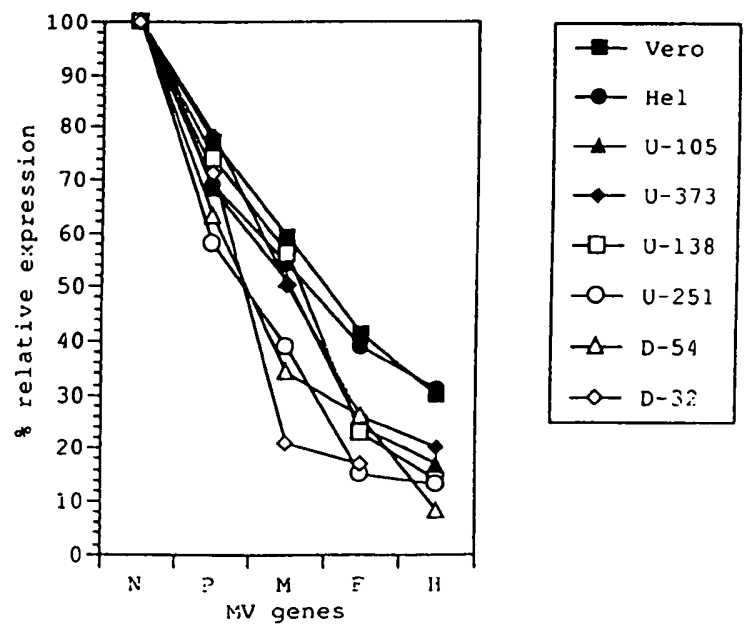

FIG. 1. Steady-state level of MV-specific monocistronic mRNAs in human glioma cells and nonneural controls. Poly $(\mathrm{A})^{+}$RNA was isolated from six human glioma cell lines and from Vero and HEL cells infected with 0.05 PFU of MV per cell for $24 \mathrm{~h}$ (panel a) and 72 $h$ (panel b) and analyzed by quantitative Northern blots with [ $\left.{ }^{32} \mathrm{P}\right]$ CTP-labeled RNA probes specific for each individual MV gene except $L(6,7)$. Signals corresponding to synthetic standard RNA transcripts and individual monocistronic MV-specific mRNAs were excised, and the radioactivity retained was determined by liquid scintillation counting. Concentration of the RNA samples was controlled by GAPDH hybridization. (a) Expression frequency of MV N gene-specific mRNA $24 \mathrm{~h}$ following infection indicated as copy number per $10 \mathrm{pg}$ of total RNA. (b) Relative expression frequencies of individual MV-specific mRNAs $72 \mathrm{~h}$ following infection compared with the individual $\mathbf{N}$ gene transcript ( $\mathbf{N}$ was set to $100 \%)$.

(Fig. 1b). In all neural cell lines tested, the relative expression frequencies of the glycoprotein-specific mRNAs were reduced compared with those found in nonneural cells. Again, compared with the nonneural cells, the relative frequencies of the $M$-specific transcripts were reduced in D-54, D-32, and U-251 cells but not in U-105, U-373, or $\mathrm{U}-138$ cells. These results indicate that host factors intrinsic to human cell lines of neural origin are capable of regulating MV transcriptional efficiency, as observed previously in a.

b.

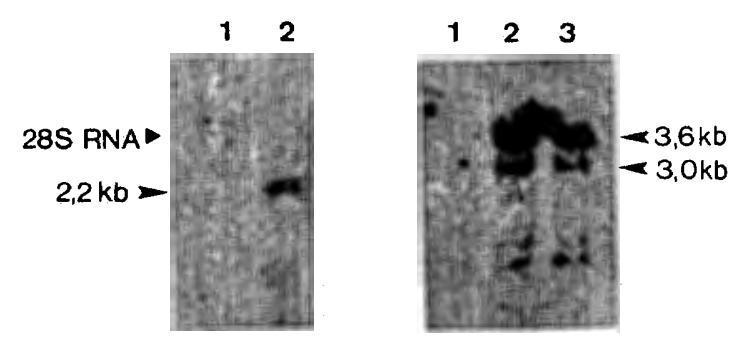

FIG. 2. Induction of glial cell-specific mRNAs in in vitro differentiated D-54 and U-251 cells. Cell lines were treated as indicated in the text or with $10 \mu \mathrm{M}$ papaverine for $72 \mathrm{~h}$. RNA (10 $\mu \mathrm{g}$ per lane) was separated on $1 \%$ formaldehyde-containing agarose gels and hybridized to cDNA probes specific for rat MBP (panel a) and mouse AMOG (panel b). (a) Lanes: 1, D-54 untreated; 2, D-54 treated with $10 \mu \mathrm{M}$ papaverine. The specific signal of $2.2 \mathrm{~kb}$ is indicated by an arrowhead, and cross-hybridization with 28S RNA is indicated by a triangle. (b) Lanes: 1, U-251 untreated; 2, U-251 treated with $200 \mu \mathrm{M}$ CPT-CAMP; 3, U-251 treated with $10 \mu \mathrm{M}$ papaverine. Specific signals of 3.6 and $3.0 \mathrm{~kb}$ are indicated by arrowheads.

brain tissue from SSPE patients and experimentally MVinfected rats and primary rat astroglial cells $(6,7,26,27)$.

In vitro difierentiation of neural cells. To investigate the effect of in vitro differentiation of our neural cell lines on MV gene expression, we treated these and the control cell lines with compounds that influence intracellular cAMP levels (1 $\mathrm{mM}$ AMP, $1 \mathrm{mM}$ cAMP, $1 \mathrm{mM}$ dibutyryl-cAMP, $1 \mathrm{mM}$ 8-bromo-cAMP, $200 \mu \mathrm{M}$ CPT-cAMP, $10 \mu \mathrm{M}$ forskolin, 1 $\mathrm{mM}$ IBMX, $10 \mu \mathrm{M}$ papaverine). As observed previously, various extents of morphological changes could be observed in all glioma cell lines following treatment with these substances $(4,34)$. To confirm differentiation, we prepared RNA from all cell lines at $72 \mathrm{~h}$ after treatment with the various substances and analyzed it for the expression of brain cell-specific mRNAs by Northern blotting. Only in two cell lines, D-54 and U-251, could the induction of these mRNAs be detected. Treatment of D-54 with $10 \mu \mathrm{M}$ papaverine induced low levels of a 2.2-kb transcript specific for MBP, a marker for oligodendrocytes (Fig. 2a, lane 2) (24). A slight cross-hybridization of this probe with 28S RNA also appeared in untreated cells (Fig. 2a, lane 1). In U-251 cells treated with $10 \mu \mathrm{M}$ papaverine or $200 \mu \mathrm{M}$ CPT-cAMP, two major mRNA species of about 3.6 and $3.0 \mathrm{~kb}$ (Fig. 2b, lanes 2 and 3) were induced that were specific for the mRNA of AMOG, a marker for astrocytes (21). Treatment with all the other compounds listed above did not lead to the expression of MBP- or AMOG-specific transcripts in either cell line (results not shown). The inducibility of MBP in D-54 cells indicates that these cells are probably of the oligodendrocyte lineage, whereas U-251 cells, which express the glial fibrillary acidic protein (4), are astrocytoma cells. No induction of these mRNAs appeared in the other glioma cells or the control cell lines (results not shown).

Replication of MV in in vitro differentiated glial cells. To analyze MV gene expression in in vitro differentiated neural cells, we studied D-54 and U-251 cells since both cell lines could be differentiated in vitro with papaverine (see above). Pretreatment of both neural cell lines with $10 \mu \mathrm{M}$ papaverine for 48,24 , and $3 \mathrm{~h}$ prior to MV infection (MOI, 0.05) reduced the titers of infectious virus after 72 and $144 \mathrm{~h}$ by up to $4 \mathrm{log}$ 
TABLE 2. Influence of in vitro differentiation on the production of infectious $M V$ in cells of neural and nonneural origin ${ }^{a}$

\begin{tabular}{|c|c|c|c|c|c|c|c|c|}
\hline \multirow{3}{*}{$\begin{array}{l}\text { Time (h before } \\
\text { infection) of } \\
\text { treatment }\end{array}$} & \multicolumn{8}{|c|}{ MV production ${ }^{b}(\mathrm{PFU} / \mathrm{ml})$ in: } \\
\hline & \multicolumn{2}{|c|}{ U-251 } & \multicolumn{2}{|c|}{ D-54 } & \multicolumn{2}{|c|}{ Vero } & \multicolumn{2}{|c|}{ HEL } \\
\hline & $72 \mathrm{~h}$ & $144 \mathrm{~h}$ & $72 \mathrm{~h}$ & $144 \mathrm{~h}$ & $72 \mathrm{~h}$ & $144 \mathrm{~h}$ & $72 \mathrm{~h}$ & $144 \mathrm{~h}$ \\
\hline $\begin{array}{l}\text { None } \\
48 \\
24 \\
3 \\
0\end{array}$ & $\begin{array}{l}1 \times 10^{4} \\
2 \times 10^{1} \\
1 \times 10^{1} \\
1 \times 10^{2} \\
3 \times 10^{3}\end{array}$ & $\begin{array}{l}6 \times 10^{5} \\
1 \times 10^{1} \\
3 \times 10^{2} \\
2 \times 10^{2} \\
2 \times 10^{3}\end{array}$ & $\begin{array}{l}1 \times 10^{4} \\
1 \times 10^{1} \\
2 \times 10^{1} \\
4 \times 10^{1} \\
3 \times 10^{2}\end{array}$ & $\begin{array}{l}4 \times 10^{5} \\
1 \times 10^{1} \\
1 \times 10^{1} \\
1 \times 10^{2} \\
1 \times 10^{3}\end{array}$ & $\begin{array}{l}6 \times 10^{6} \\
1 \times 10^{7} \\
5 \times 10^{6} \\
1 \times 10^{7} \\
1 \times 10^{7}\end{array}$ & $\begin{array}{l}\mathbf{N D}^{c} \\
\mathbf{N D} \\
\mathbf{N D} \\
\mathbf{N D} \\
\mathbf{N D}\end{array}$ & $\begin{array}{l}1 \times 10^{5} \\
6 \times 10^{4} \\
2 \times 10^{5} \\
6 \times 10^{4} \\
2 \times 10^{5}\end{array}$ & $\begin{array}{l}2 \times 10^{6} \\
4 \times 10^{5} \\
5 \times 10^{5} \\
2 \times 10^{5} \\
1 \times 10^{6}\end{array}$ \\
\hline
\end{tabular}

a Cells were pretreated with $10 \mu \mathrm{M}$ papaverine for the time intervals indicated or left untreated and infected with $\mathrm{MV}$ at 0.05 PFU per cell for 72 and $144 \mathrm{~h}$. Supernatants were harvested, and their titers were determined on Vero cells.

$b$ Values are means from two independent experiments.

c ND, not done (cells were destroyed).

units compared with the untreated controls. Treatment of cells with papaverine simultaneously with the infection was less effective (Table 2). No significant influence on the virus yield could be observed in papaverine-treated Vero and HEL cells (Table 2).

In addition, we could show by immunofluorescent staining with polyclonal sera and monoclonal antibodies that after pretreatment of D-54 and $U-251$ cells with $10 \mu \mathrm{M}$ papaverine for $48 \mathrm{~h}$, the expression of the major MV structural proteins was reduced to almost undetectable levels 72 and $144 \mathrm{~h}$ following infection (results not shown).

Steady-state level of MV-specific RNAs in in vitro differentiated human glioma cells. To determine the basis for the restrictions of MV replication that we observed, we analyzed the frequency of MV-specific transcripts in undifferentiated or differentiated D-54 and U-251 cells after 72 and $144 \mathrm{~h}$ of infection by using quantitative Northern blots with poly(A)-enriched RNA fractions (Table 3 ). Differentiation was induced by pretreatment with $10 \mu \mathrm{M}$ papaverine for 48 $h$ prior to infection. Equal amounts of RNA were blotted in all experiments as controlled by a GAPDH hybridization (results not shown). For D-54 cells, no significant differences in the levels of monocistronic MV-specific transcripts could be observed after $72 \mathrm{~h}$ in differentiated and undifferentiated cells, except that the mRNA gradient from $\mathrm{N}$ to $\mathrm{H}$ appeared to be slightly steeper in differentiated cells (Table 3). After 6 days of infection, however, the total amount of MV-specific mRNAs was reduced by more than $50 \%$ compared with that in the untreated control as monitored by the frequency of
$\mathrm{N}$-specific transcripts, whereas the gradient remained substantially stable (Table 3 ). For U-251 cells, a reduction in the level of the MV N-specific mRNA was already apparent after $72 \mathrm{~h}$ ( $50 \%$ of control levels), and by $144 \mathrm{~h}$ following infection, a steep gradient of transcription similar to that in D-54 cells was established (Table 3 ).

To assess the biological activity of the isolated mRNAs, we performed in vitro translation experiments (Fig. 3, lanes 1 to 7). Following immunoprecipitation of the translation products, the $\mathbf{N}, \mathbf{P}$, and $\mathbf{M}$ proteins ( $\mathrm{M}$ migrating as double band) were detected in the undifferentiated D-54 and U-251 cells and in Vero cells (lanes 8, 9, and 12). F and $H$ proteins usually cannot be detected in these assays because of the low expression levels of the corresponding mRNAs and the lack of antibodies that would recognize the proteins synthesized in vitro. Following differentiation of D-54 cells by 10 $\mu \mathrm{M}$ papaverine for 24 and $48 \mathrm{~h}$ prior to infection, the biological activity of the MV-specific mRNA fractions isolated after $72 \mathrm{~h}$ of infection (lanes 10 and 11) was not altered compared with that of the untreated control cells (lane 9). Poly(A) ${ }^{+}$RNA isolated from differentiated U-251 cells appeared to direct the synthesis of slightly lower levels of MV-specific proteins, in particular $M$ protein, in vitro compared with the untreated control (lanes 12 and 14). This finding might be because at the same time the relative amount of MV-specific transcripts was reduced by $50 \%$ in differentiated U-251 cells compared with the undifferentiated control (Table 3).

Thus, in vitro differentiation of U-251 but not of D-54 cells

TABLE 3. Quantitative analysis of MV-specific transcription in in vitro differentiated and undifferentiated D-54 and U-251 cells ${ }^{a}$

\begin{tabular}{|c|c|c|c|c|c|c|c|c|c|}
\hline \multirow{4}{*}{ Protein } & \multicolumn{9}{|c|}{ Frequency (copies/cell) of MV-specific transcripts (\%) in ${ }^{b}$ : } \\
\hline & \multirow{3}{*}{$\begin{array}{c}\text { Vero, } \\
\text { untreated, } \\
72 \mathrm{~h}\end{array}$} & \multicolumn{4}{|c|}{ D-54 } & \multicolumn{4}{|c|}{$\mathrm{U}-251$} \\
\hline & & \multicolumn{2}{|c|}{ Untreated } & \multicolumn{2}{|c|}{$10 \mu \mathrm{M}$ papaverine } & \multicolumn{2}{|c|}{ Untreated } & \multicolumn{2}{|c|}{$10 \mu \mathrm{M}$ papaverine } \\
\hline & & $72 \mathrm{~h}$ & $144 \mathrm{~h}$ & $72 \mathrm{~h}$ & $144 \mathrm{~h}$ & $72 \mathrm{~h}$ & $144 \mathrm{~h}$ & $72 \mathrm{~h}$ & $144 \mathrm{~h}$ \\
\hline $\begin{array}{l}\mathbf{N} \\
\mathbf{P} \\
\mathbf{M} \\
\mathbf{F} \\
\mathbf{H}\end{array}$ & $\begin{array}{c}19,700(100) \\
15,500(78) \\
11,000(56) \\
8,500(43) \\
6,300(32)\end{array}$ & $\begin{array}{c}6,000(100) \\
3,800(63) \\
2,000(34) \\
1,500(26) \\
500(8)\end{array}$ & $\begin{array}{c}4,800(100) \\
4,000(80) \\
1,550(33) \\
800(17) \\
500(12)\end{array}$ & $\begin{array}{c}6,700(100) \\
5,200(77) \\
1,430(21) \\
700(10) \\
400(6)\end{array}$ & $\begin{array}{c}2,000(100) \\
1,500(75) \\
500(25) \\
330(16) \\
345(17)\end{array}$ & $\begin{array}{c}7,000(100) \\
3,200(46) \\
2,400(35) \\
1,400(20) \\
700(10)\end{array}$ & $\begin{array}{c}6,800(100) \\
4,600(68) \\
3,000(44) \\
1,000(15) \\
900(14)\end{array}$ & $\begin{array}{c}3,400(100) \\
2,500(74) \\
1,600(47) \\
800(24) \\
600(17)\end{array}$ & $\begin{array}{c}2,700(100) \\
1,700(64) \\
600(21) \\
110(4) \\
100(4)\end{array}$ \\
\hline
\end{tabular}

a Cells were pretreated with $10 \mu \mathrm{M}$ papaverine for $48 \mathrm{~h}$ or left untreated; they were then infected with 0.05 PFU of MV per cell. Poly $(A)^{+}$RNA fractions were harvested 72 and $144 \mathrm{~h}$ later, and a mixture of synthetic standard RNA transcripts was separated on $1.5 \%$ agarose gels, blotted, and hybridized as described previously (27). Signals corresponding to the monocistronic MV-specific mRNAs and the synthetic standard RNA transcripts were excised, and radioactivity retained was determined by scintillation counting.

$\checkmark$ Values shown as copies/cell indicate the absolute copy number per transcript for one infected cell (roughly for 10 pg of RNA), and the percentages indicate the relative expression frequencies with respect to the transcription frequency of the individual $\mathbf{N}$ gene transcript $(\mathbf{N}=100 \%)$. 


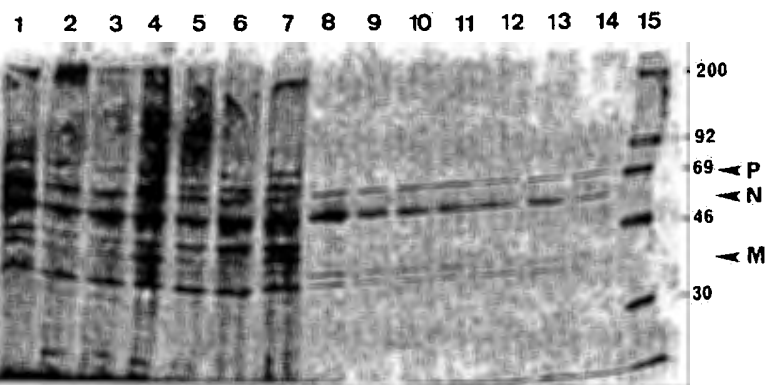

FIG. 3. In vitro translation of mRNAs isolated from in vitro differentiated and undifferentiated D-54 and U-251 cells. Each $1 \mu \mathrm{g}$ of poly $(\mathrm{A})^{+} \mathrm{RNA}$ isolated from in vitro differentiated or undifferentiated D-54 and U-251 cells $72 \mathrm{~h}$ following infection with 0.05 PFU of MV per cell was translated in vitro in the presence of $\left[{ }^{35}\right.$ S $]$ methionine (lanes 1 to 7 ). MV-specific proteins were precipitated from the total translation products by an MV hyperimmune serum and separated by PAGE (10\% polyacrylamide) (lanes 8 to 14). Lanes: 1 and 8, lytically infected Vero cells; 2 and 9, D-54 cells untreated; 3 and 10, D-54 cells differentiated with $10 \mu \mathrm{M}$ papaverine for $24 \mathrm{~h} ; 4$ and 11, D-54 cells differentiated with $10 \mu \mathrm{M}$ papaverine for $48 \mathrm{~h} ; 5$ and 12, U-251 cells untreated; 6 and 13, U-251 cells differentiated with $10 \mu \mathrm{M}$ papaverine for $24 \mathrm{~h} ; 7$ and $14, \mathrm{U}-251$ cells differentiated with $10 \mu \mathrm{M}$ papaverine for $48 \mathrm{~h}$.

was accompanied by quantitative transcriptional alterations of MV-specific mRNAs $72 \mathrm{~h}$ following infection. Since an inhibition of the biological activity of these MV-specific mRNAs could not be observed in vitro, the significant down-regulation of MV replication observed for both cell lines in vivo must be caused by additional mechanisms.

Translation of MV-specific proteins in in vitro differentiated glial cells. To monitor MV-specific protein synthesis in differentiated neural cells, we pretreated D-54 and U-251 cells with papaverine for $48 \mathrm{~h}$, infected them with MV (MOI, $0.05)$, and labeled them with $\left[{ }^{35}\right.$ S $]$ methionine after various times up to $144 \mathrm{~h}$ following infection. Total lysates were immunoprecipitated by using a polyclonal MV hyperimmune serum. In untreated D-54 and U-251 cells, MV N, P, M, and $H$ proteins could be detected after 72 and $144 \mathrm{~h}$ of infection (Fig. 4a and c). In lysates prepared from cells pretreated with papaverine for $48 \mathrm{~h}$, hardly any MV-specific proteins could be found (Fig. 4b and d). This effect appeared to be specific for MV proteins, since no effect on total-protein synthesis was evident in unprecipitated lysates (results not shown). Thus, a specific, differentiation-dependent inhibition of MV protein synthesis in the presence of significantly large amounts of MV-specific mRNAs (Table 3) was apparent in neural cells.

To release the differentiation-dependent block and to reactivate translation from the accumulated MV-specific transcripts, U-251 cells we pretreated as described above and, after infection for $72 \mathrm{~h}$ with MV (MOI, 0.05), papaverine was removed for $6 \mathrm{~h}$ and cells were labeled with $\left.{ }^{35} \mathrm{~S}\right]$ methionine for a further $2 \mathrm{~h}$. Following immunoprecipitation, MV N-specific signals were quantified by phosphorimaging. Pretreatment with papaverine led to a drastic reduction of MV N-specific protein synthesis by $90 \% \mathrm{com}$ pared with control cells (Fig. 5, lanes 2 and 4). At $6 \mathrm{~h}$ following removal of the differentiation medium, an approximately fivefold increase in the expression of $\mathbf{N}$ protein could be observed (lane 3 ). The expression level obtained for $\mathbf{N}$ protein under these conditions was about $50 \%$ of that achieved after a primary infection for $6 \mathrm{~h}$ with $\mathrm{MV}$ at an MOI a.

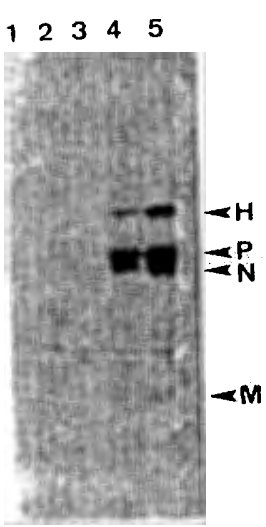

C.

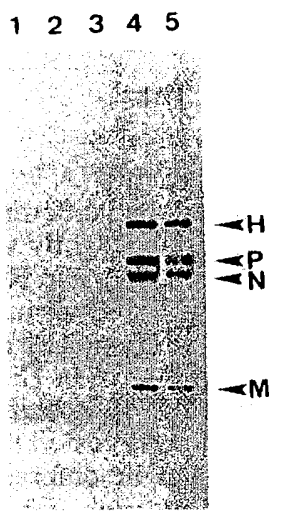

b.

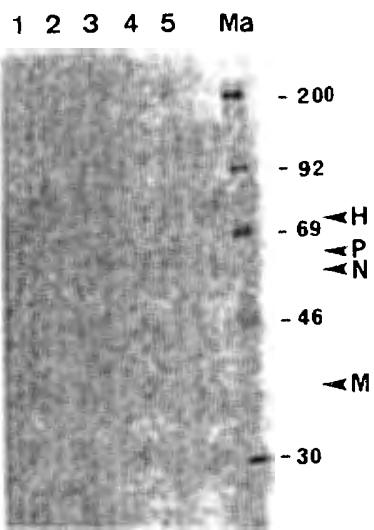

d.

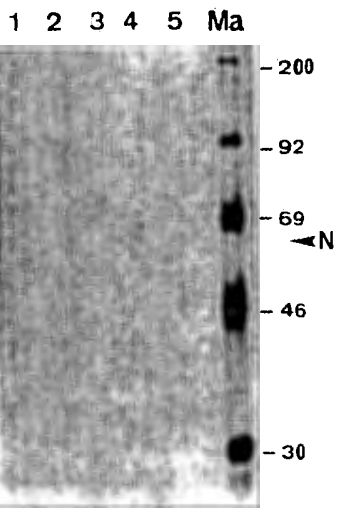

FIG. 4. In vivo synthesis of MV-specific proteins in in vitro differentiated and undifferentiated D-54 and U-251 cells. D-54 (panels $a$ and b) and U-251 (panels $c$ and d) cells were pretreated for 48 $h$ (panels b and d) with $10 \mu \mathrm{M}$ papaverine or left untreated (panels a and c) and infected with MV (MOI, 0.05). Immediately following infection (lanes 1 ) or $3 \mathrm{~h}$ (lanes 2), $6 \mathrm{~h}$ (lanes 3), $72 \mathrm{~h}$ (lanes 4 ), or 144 $\mathrm{h}$ (lanes 5) after infection, cells were labeled for $2 \mathrm{~h}$, and total lysates were prepared and immunoprecipitated with MV hyperimmuneserum. Proteins were separated by PAGE ( $10 \%$ polyacrylamide). Lanes Ma contain ${ }^{14} \mathrm{C}$-methylated protein size markers.

of 5 (lane 1). Given the short time and the extremely low level of infectious MV present in the medium under these conditions (Table 2), the increase in MV protein expression following removal of the differentiation medium reflects a release of the translational block of accumulated viral mRNAs.

Inhibition of primary MV gene expression in differentiated glial cells. To investigate whether the differentiation-dependent block in viral protein synthesis in the presence of ongoing transcription can be observed under conditions other than several days after infection with low-input MOIs, we assessed the effects of in vitro differentiation on primary MV gene expression by using higher MOI. As exemplified for U-251 cells, parallel cultures untreated or pretreated with $10 \mu \mathrm{M}$ papaverine for $48 \mathrm{~h}$ were infected with $\mathrm{MV}$ at an MOI of 1 for $18 \mathrm{~h}$ and analyzed for the steady-state level of MV $\mathrm{N}$-specific mRNA and MV-specific protein expression in 


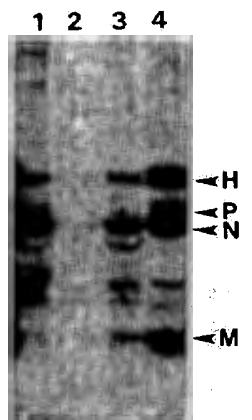

FIG. 5. Reactivation of MV protein synthesis following removal of the differentiation medium. U-251 cells were pretreated with 10 $\mu \mathrm{M}$ papaverine for $48 \mathrm{~h}$ (lanes 2 and 3) or left untreated (lanes 1 and 4). Cells were infected with an MOI of 0.05 (lanes 2 to 4). After 72 $\mathrm{h}$, the differentiation medium was removed, cells were washed carefully, and infection was allowed to proceed for a further $6 \mathrm{~h}$ (lane 3). For a control, U-251 cells were infected with an MOI of 5 for $6 \mathrm{~h}$ (lane 1). Following a 2-h labeling period with ${ }^{35}$ S $]$ methionine lysates were prepared and immunoprecipitated with an anti-MV hyperimmune serum. Proteins were separated by PAGE $(10 \%$ polyacrylamide). The MV N-specific signals were quantitated with a phosphorimager.

vivo. Comparable amounts of $\mathrm{N}$-specific mRNA were expressed in undifferentiated (Fig. 6a, lane 1) and differentiated (Fig. 6a, lane 2) U-251 cells. The apparently slightly weaker signal for the N monocistronic and NP bicistronic RNA in differentiated U-251 cells (Fig. 6a, lane 2) is because not exactly equal amounts of total RNA were applied for gel analysis as controlled by GAPDH hybridization (Fig. 6a, bottom panel). A quantitative analysis of MV-specific protein expression at the same time, however, revealed that the levels of MV-specific protein expression in differentiated U-251 cells were reduced to $25 \%$ for $N$ proteins and to $13 \%$ for $\mathbf{H}$ and $M$ proteins of the untreated controls (Fig. $6 \mathrm{~b}$ ). Reliable data on virus release even in the untreated control cells could not be obtained because of the short duration of infection. These data indicate that in differentiated cells

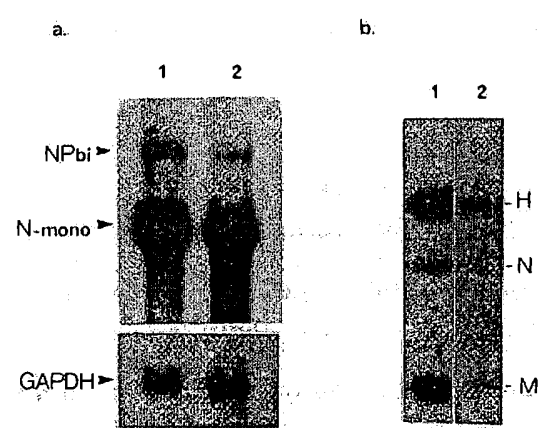

FIG. 6. Effect of in vitro differentiation on primary MV gene expression. Parallel cultures of U-251 cells were pretreated with 10 $\mu \mathrm{M}$ papaverine for $48 \mathrm{~h}$ (lanes 2) or left untreated (lanes 1) and infected with MV at an MOI of 1 for $18 \mathrm{~h}$. The signals obtained were quantitated by phosphorimaging. (a) Each $15 \mu \mathrm{g}$ of total cellular RNA was hybridized to a MV N-specific (upper panel) or GAPDHspecific (bottom panel) probe. $\mathrm{N}$-mono, $\mathrm{N}$-specific monocistronic RNA; NPbi, NP bicistronic RNA. (b) Immunoprecipitation of MV-specific proteins labeled after $18 \mathrm{~h}$ of infection with an MOI of 1. a.

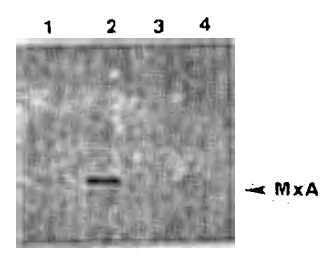

b.

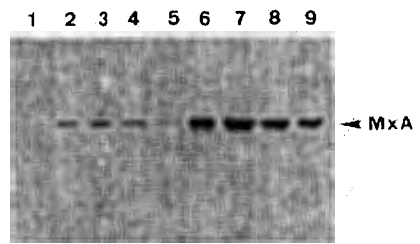

FIG. 7. Induction of type I IFN in D-54 cells. (a) D-54 cells were cultured without additives (lane 1 ) or treated for $18 \mathrm{~h}$ with $500 \mathrm{U}$ of human IFN- $\beta$ (lane 2) or for $48 \mathrm{~h}$ with $10 \mu \mathrm{M}$ papaverine (lane 3 ) or $200 \mu \mathrm{M}$ CPT-cAMP (lane 4). Each $20 \mu \mathrm{g}$ of protein extract was separated by PAGE ( $10 \%$ polyacrylamide), blotted onto nitrocellulose filters, stained with a monoclonal antibody against human MxA (p78) (13), and developed with $\mathrm{H}_{2} \mathrm{O}_{2}$. (b) D-54 cells were cultured without additives (lanes 2 and 6 ) or pretreated for $48 \mathrm{~h}$ with $200 \mu \mathrm{M}$ CPT-cAMP (lanes 3 and 7), $10 \mu \mathrm{M}$ papaverine (lanes 4 and 8 ), or $1 \mathrm{mM}$ dibutyryl-cAMP (lanes 5 and 9) prior to infection with MV (MOI, 0.05). Protein extracts were prepared after $24 \mathrm{~h}$ (lanes 2 to 5 ) or $48 \mathrm{~h}$ (lanes 6 to 9) of infection. Lane 1 contains extract from uninfected D-54 cells. Each $50 \mu \mathrm{g}$ of total cell extract was separated by PAGE ( $10 \%$ polyacrylamide), blotted, and stained for MxA.

of neural origin the synthesis of MV-specific proteins but not of mRNAs is already inhibited within the first replication cycle.

Restriction of MV-specific protein synthesis in glial cells is not linked to type I IFN. To assess the possibility that the virus-specific restriction of protein synthesis was due to the induction of type I interferon (IFN) by papaverine in D-54 and U-251 cells, supernatants of papaverine-treated cells infected or uninfected with MV were assayed for type I IFN. No evidence for type I IFN induction could be obtained in a vesicular stomatitis virus (VSV) bioassay. Therefore, as a more sensitive test system for IFN synthesis, the intracellular induction of the human MxA protein was analyzed by Western blotting. Except for the positive control performed with recombinant IFN- $\beta$, MxA was not induced by any of the compounds applied, as exemplified for D-54 cells (Fig. $7 a$, lane 2). MV infection itself induced significant amounts of MXA within 24 and $48 \mathrm{~h}$ in both cell lines independent of the pretreatment with papaverine or CPT-cAMP (shown for D-54 in Fig. 7b). In addition, the induction of MxA in both cell lines following infection with MV could be blocked by about $60 \%$ in the presence of anti-IFN- $\beta$ antibodies (data not shown). Thus, MV infection induced type I IFN which was not detectable in the VSV bioassay but was clearly demonstrable in the MxA induction assay. Therefore, the observed restriction of MV-specific protein synthesis was not due to a hyperinduction of type I IFN by papaverine or CPT-cAMP treatment of glioma cells but appears to result from different mechanisms. 


\section{DISCUSSION}

Host cell-dependent down-regulation of MV gene expression may be crucial for the establishment of persistent infections in human brain tissue $(5,28)$. Transcriptional regulation of MV-specific monocistronic mRNAs leading to highly polar transcription gradients have been described for brain tissue from patients with SSPE and for experimentally induced central nervous system infections in rats and in tissue cultures with primary rat astroglial cells $(6,7,26,27)$. We now provide experimental evidence that this particular regulation and a down-regulation of MV protein synthesis occur in an experimental system involving homologous human cells of neural origin, indicating that factors intrinsic to the host cell do affect MV expression.

As shown previously for primary rat astroglial cells (27), the level of viral transcripts as measured by the expression of the N-specific mRNA was found to be reduced during infection in all neural cell lines compared with that in Vero and HEL cells (Fig. 1a). Since we used low MOIs for the experiments, the neural cell lines show a reduced capacity to replicate MV, which might be due to a lower activity of the viral transcription complex. As found typically in brain tissue, transcription of the glycoprotein-specific mRNAs was significantly attenuated in all the neural cell lines. These findings indicate that the analysis of brain cell-specific factors regulating MV transcription can be addressed in the future by using permanent human cell lines.

Mx proteins have been shown to interfere with influenza virus and VSV replication $(17,22,29)$. Recently, a downregulation of VSV transcription accompanied by the establishment of a more polar transcription gradient for monocistronic transcripts in stably MxA-transfected Swiss 3T3 cells has been observed (30). Interestingly, we could detect a differentiation-independent induction of type I IFN, most probably IFN- $\beta$, and the IFN-inducible MxA protein on MV infection in D-54 and U-251 cells (Fig. Tb). In addition, high levels of Mx proteins were found in MV-infected primary rat astroglial cells (16). Whether MxA protein contributes to transcriptional or translational regulation of $\mathrm{MV}$ remains to be investigated.

In our experiments, we analyzed a variety of substances affecting the intracellular cAMP level of tissue culture cells for their influence on MV replication. In general, membranepermeable analogs of cAMP and phosphodiesterase inhibitors such as IBMX and papaverine revealed an inhibitory effect. Papaverine, a potent inhibitor of a variety of phosphodiesterases (23), had been previously shown to inhibit the replication of MV $(18,35)$ and human immunodeficiency virus (33) but not herpes simplex virus type 1 or VSV (18). Elevation of the intracellular cAMP concentration, which is coincident with differentiation, also led to a down-regulation of viral gene expression of mouse hepatitis virus JHM in explanted rat oligodendrocytes (3).

A complete inhibition of MV transcription following treatment with papaverine has been described in human neuroblastoma IMR 32 cells (35). In contrast, our data suggest that translation, not transcription, is the primary target for downregulation of MV gene expression following in vitro differentiation in D-54 and U-251 cells. We found that papaverine treatment was already inhibiting the translation of MVspecific proteins after $18 \mathrm{~h}$ of infection (Fig. 6b). These alterations of translation were observed in the presence of equal amounts of viral mRNAs in the cultures and within a short time, indicating that they occur independently of virus spread. The down-regulation of transcription observed at 72 and $144 \mathrm{~h}$ following infection may be a consequence of the low synthesis of MV proteins essential for viral transcription, replication, and, ultimately, spread.

Following papaverine treatment, a reduced synthesis of all MV structural proteins in 118-MGC cells (35) and a selective disappearance of MV M protein in mouse N2A and human TE671 cells (18) was observed, whereas pretreatment of human AV3 cells with cAMP led to a reduced synthesis of MV $P$ and $M$ proteins (25). Although no analyses on the expression of virus-specific mRNAs have been performed, those experiments clearly indicate that a complete inhibition of transcription did not occur. This applies in particular to the selective disappearance of $P$ and $M$ proteins that are translated from mRNAs located upstream of the MV glycoprotein genes, whereas $F$ and $H$ were still expressed at normal levels $(18,25)$. The obvious discrepancy of these and our findings to the complete inhibition of MV-specific transcription in human neuroblastoma IMR-32 cells is still unsolved. In view of the fact, however, that the distribution of cAMP-dependent protein kinases as well as phosphodiesterases is highly cell type specific (2), external treatment with compounds affecting the intracellular cAMP level could have variable effects on MV gene expression.

Selective inhibition of viral protein synthesis in vivo has been studied intensively for the IFN-inducible P1 kinase (14, $29,32)$, which is activated on autophosphorylation and inactivates the $\alpha$-subunit of translation initiation factor eIF-2 by phosphorylation (14). Type I IFN was induced on MV infection in both cell lines analyzed, as shown by the induction of MxA protein. This induction, however, was not enhanced by papaverine treatment in infected cells, nor was papaverine alone able to induce type I IFN in either cell line (Fig. 7). Although it could be shown that the activity of P1 kinase can be modulated by external stimuli others than IFN (10), it has been shown to be completely independent of cAMP (1).

The reason for the failure of MV-specific mRNAs to direct the synthesis of structural proteins in vivo in differentiated cells is not known. A selective translational inhibition had been described for MV M and F mRNAs after a temperature shift in vivo, although these mRNAs retained their biological activity in a cell-free translation system $(19,20)$. It is possible that the interaction of the mRNAs with the cytoskeleton, which seems to be crucial for efficient translation (8) in vivo, is dependent on stress or differentiation factors.

Furthermore, functions of the viral polymerase essential for processing and maturation of the viral transcripts might be impaired in in vitro differentiated cells. Defects in polyadenylation would not be expected, since the polyadenylated fraction of RNAs isolated from in vitro differentiated D-54 and U-251 cells was biologically active in directing the synthesis of MV-specific proteins in vitro (Fig. 4) corresponding to the abundance of MV-specific mRNAs (Table 3 ). We cannot rule out the possibility, however, that capping modifications did occur, since the in vitro translation system is able to translate most mRNAs independent of cap structures. In fact, it could be shown for a host range polymerase mutant of VSV that cap-methylation-defective transcripts were translated correctly in vitro but not in vivo in the nonpermissive cell line (12). In that case, however, the efficiency of in vitro translation for the undermethylated transcripts was significantly lower than that of the completely methylated mRNAs. Although the amounts of MV specific transcripts synthesized in our experiments in vitro from polyadenylated mRNAs from differentiated and undif- 
ferentiated glial cells after $72 \mathrm{~h}$ seemed to be identical, we cannot rule out the possibility that the commercial in vitro translation system we used is not as sensitive to this effect as was the system used for the VSV study. As an example of translational control of viral mRNAs exerted by the host cell, the interaction of picornavirus mRNA with cellular proteins that facilitate cap-independent internal initiation of translation has recently been described (9).

These findings suggest that a particular host cell may contain the necessary components to regulate the translational efficiency of viral transcripts. Control at the level of MV-specific translation exerted by the infected brain cell would provide a highly potent mechanism to down-regulate MV gene expression in vivo. Taken together, our findings indicate that differentiated brain cells may be able to downregulate viral transcription as well as viral translation. Both mechanisms might contribute to the establishment of persistent MV infections of the central nervous system.

\section{ACKNOWLEDGMENTS}

We thank Sue Moyer, Ulrich Walter, and Susan Lohmann for helpful discussions; Michel A. Horisberger for the antibody against the human MxA; and Lee Dunster and Sue Moyer for critical reading of the manuscript.

This work was supported by the Deutsche Forschungsgemeinschaft.

\section{REFERENCES}

1. Atwater, J. A., and C. E. Samuel. 1982. Interferon inhibits the synthesis of viral proteins and induces P1 phosphorylation in both adenylate cyclase deficient and cAMP dependent protein kinase deficient variants of mouse lymphoma cells. Virology 123:206-211.

2. Beavo, J. A. 1990 . Multiple isoenzymes of cyclic nucleotide phosphodiesterases. Adv. Second Messenger Protein Phosphorylation Res. 22:11-75.

3. Beushausen, S., S. Narindrasorasak, B. D. Sanwal, and S. Dales. 1987. In vivo and in vitro models of demyelinating disease: activation of the adenylate cyclase system influences JHM expression in explanted rat oligodendrocytes. J. Virol. 61:37953803.

4. Bigner, D. D., S. H. Bigner, J. Ponten, B. Westermark, M. S. Mahaley, E. Ruoslahti, H. Herschman, L. F. Eng, and C. J. Wikstrand. 1981. Heterogeneity of genotypic and phenotypic characteristics of fifteen permanent cell lines derived from human gliomas. J. Neuropathol. Exp. Neurol. XL:201229.

5. Billeter, M. A., and R. Cattaneo. 1991. Molecular biology of defective measles viruses persisting in the human central nervous system, p. 323-345. In D. Kingsbury (ed.), The paramyxoviruses. Plenum Press, New York.

6. Cattaneo, R., G. Rebmann, K. Baczko, V. ter Meulen, and M. A. Billeter. 1987. Altered ratios of measles virus transcripts in diseased human brains. Virology 160:523-526.

7. Cattaneo, R., G. Rebmann, A. Schmid, K. Baczko, V. ter Meulen, and M. A. Billeter. 1987. Altered transcription of a defective measles virus genome derived from a diseased human brain. EMBO J. 6:681-687.

8. Cervera, M., G. Dreyfuss, and S. Penman. 1981. Messenger RNA is translated when associated with the cytoskeletal framework in normal and VSV-infected HeLa cells. Cell 23:113120.

9. Dildine, S. L., and B. L. Semler. 1992. Conservation of RNAprotein interactions among picornaviruses. J. Virol. 66:4364 4376.

10. Dubois, M. F., J. Galabru, P. Lebon, B. Safer, and A. G. Hovanessian. 1989. Reduced activity of the interferon-induced double stranded RNA dependent protein kinase activity during heat shock. J. Biol. Chem. 264:12165-12171.

11. Fort, P., L. Marty, M. Piechaczyk, S. Elsalrouty, C. Dani, P. Janteur, and J. M. Blanchard. 1985. Various rat adult tissues express only one major mRNA species from the glyceraldehyde-3-phosphate dehydrogenase. Nucleic Acids Res. 13:14311442.

12. Horikami, S. M. and S. A. Moyer. 1982. Host range mutants of vesicular stomatitis defective in in vitro RNA methylation. Proc. Natl. Acad. Sci. USA 79:7694-7698.

13. Horisberger, M. A., and H. K. Hochkeppel. 1987. IFN $\alpha$ induced human $78 \mathrm{kD}$ protein: purification and homologies with the mouse Mx protein, production of monoclonal antibodies and potentiation effect of IFN $\gamma$. J. Interferon Res. 7:331-343.

14. Jacobs, B. L., N. G. Miyamoto, and C. E. Samuel. 1988. Mechanisms of interferon action: studies on the activation of protein phosphorylation and the inhibition of translation in cell free systems. J. Interferon Res. 8:617-631.

15. Kobune, K., F. Kobune, K. Yamanouchi, K. Nagashima, Y. Yoshikawra, and M. Hayami. 1983. Neurovirulence of rat brain adapted measles virus. Jpn. J. Exp. Med. 53:177-180.

16. Kraus, E., S. Schneider-Schaulies, M. Miyasaka, T. Tamatani, and J. Sedgwick. 1991. Augmentation of major histocompatibility complex class I and ICAM-1 expression on glial cells following measles virus infection: evidence for the role of type-1 interferon. Eur. J. Immunol. 22:175-182.

17. Meier, E., G. Kunz, O. Haller, and H. Arnheiter. 1990. Activity of rat Mx proteins against rhabdoviruses. J. Virol. 64:62636269.

18. Miller, C. A., and D. R. Carrigan. 1982. Reversible repression and activation of measles virus infection in neural cells. Proc. Natl. Acad. Sci. USA 79:1629-1633.

19. Ogura, H., K. Baczko, B. K. Rima, and V. ter Meulen. 1987. Selective inhibition of translation of the mRNA coding for measles virus membrane protein at elevated temperatures. J. Virol. 61:472-479.

20. Ogura, H., B. K. Rima, K. Baczko, and V. ter Meulen. 1988. Restricted synthesis of the fusion protein of measles virus at elevated temperatures. J. Gen. Virol. 69:925-929.

21. Pagliusi, S., H. Antonicek, S. Gloor, R. Frank, M. Moos, and M. Schachner. 1989. Identification of a cDNA clone specific for the neural cell adhesion molecule AMOG. J. Neurosci. Res. 22:113119.

22. Pavlovic, J., T. Zürcher, O. Haller, and P. Staeheli. 1990. Resistance to influenza virus and vesicular stomatitis virus conferred by expression of human MxA protein. J. Virol. 64:3370-3375.

23. Poch, G., and W. R. Kukovetz. 1971. Papaverine induces inhibition of phosphodiesterases activity in various mammalian tissues. Life Sci. 10:251-290.

24. Roach, A., K. Boylan, S. Horvath, S. B. Prusiner, and L. E. Hood. 1983. Characterization of a cloned cDNA representing myelin basic protein: absence of expression in brain of shiverer mutant mice. Cell 34:799-806.

25. Robbins, S. J., and F. Rapp. 1980. Inhibition of measles virus replication by cyclic AMP. Virology 106:317-326.

26. Schneider-Schaulies, S., U. G. Liebert, K. Baczko, R. Cattaneo, M. A. Billeter, and V. ter Meulen. 1989. Restriction of measles virus gene expression in acute and subacute encephalitis of Lewis rats. Virology 171:524-534.

27. Schneider-Schaulies, S., U. G. Llebert, K. Baczko, and V. ter Meulen. 1990. Restricted expression of measles virus in primary rat astroglial cells. Virology 177:802-806.

28. Schneider-Schaulies, S., and V. ter Meulen. 1992. Molecular aspects of measles virus induced central nervous system diseases, p. 419-449. In R. P. Roos (ed.), Molecular neurovirology. Humana Press Inc., Clifton, N.J.

29. Staeheli, P. 1990. Interferon induced proteins and the antiviral state. Adv. Virus Res. 38:147-200.

30. Staeheli, P., and J. Pavlovic. 1991. Inhibition of vesicular stomatitis virus mRNA synthesis by human MxA protein. $J$. Virol. 65:4498-4501.

31. ter Meulen, V., J. R. Stephenson, and H. W. Kreth. 1983. Subacute sclerosing panencephalitis, p. 105-159. In H. Fraen- 
kel-Conrat and R. R. Wagner (ed.), Comprehensive virology, vol. 18. Plenum Press, New York.

32. Thomis, D. C. J. P. Doohan, and C. E. Samuel. 1992. Mechanisms of interferon action: cDNA-structure, expression and regulation of the interferon-induced, RNA dependent P1/elF-2 $\alpha$ protein kinase from human cells. Virology 188:33-46.

33. Turano, A. G. Scura, A. Caruso, C. Bonfanti, R. Luzzati, D. Basseti, and N. Manca. 1989. Inhibitory effect of papaverine on
HIV replication in vitro. AIDS Res. Hum. Retroviruses 5:183-192. 34. Wikstrand, C. J., F. C. Grahmann, R. D. McComb, and D. D. Bigner. 1985. Antigenic heterogeneity of human anaplastic gliomas and glioma-derived cell lines defined by monoclonal antibodies. J. Neuropathol. Exp. Neurol. 44:229-241.

35. Yoshikawa, Y., and K. Yamanouchi. 1984. Effects of papaverine treatment on replication of measles virus in human neural and nonneural cells. J. Virol. 50:489-496. 